\title{
Magnetic properties of Triassic rocks of Svalbard Archipelago: preliminary results
}

\author{
Katarzyna Dudzisz ${ }^{1}$, Rafał Szaniawski ${ }^{1}$, Krzysztof Michalski ${ }^{1}$, \\ Krzysztof Krajewski ${ }^{2}$
}

${ }^{1}$ Polish Academy of Sciences - Centre for Polar Studies KNOW (Leading National Research Centre), Institute of Geophysics; ul. Księcia Janusza 64,01-452 Warsaw, Poland; e-mail: kdudzisz@igf.edu.pl

${ }^{2}$ Polish Academy of Sciences, Institute of Geological Sciences; ul. Twarda 51/55, 00-818 Warsaw, Poland

(C) 2015 Authors. This is an open access publication, which can be used, distributed and reproduced in any medium according to the Creative Commons CC-BY 4.0 License requiring that the original work has been properly cited.

Studies were carried out in three rock formations: the Vardebukta Formation (Early Triassic) and the Bravaisberget Formation (Middle Triassic) from Spitsbergen and the Botneheia Formation (Middle Triassic) from Edgeøya (Eastern Svalbard). Collected samples are diversified and represent various lithologies with different thermal and tectonic histories. Magnetic properties of the specimens were studied using rock-magnetic methods including: thermal demagnetization of saturated isothermal remanent magnetization (SIRM), hysteresis loops and analysis of magnetic susceptibility variations at high temperatures. Subsequently anisotropy of magnetic susceptibility (AMS) and analysis of the structure of natural remanent magnetization (NRM) using thermal and alternating field (AF) demagnetization were investigated. The obtained results show that magnetite represents the main magnetic mineral in all studied rocks, whereas pyrrothite, as a second magnetic information carrier, was noted in some of specimens only. The samples from Edgeøya possess the highest magnetic susceptibility (ca. $240 \cdot 10^{-6} \mathrm{SI}$ ) which tends to decrease in sites located further to the west and reaches the minimum value for samples from western Spitsbergen (ca. $\left.30-40 \cdot 10^{-6} \mathrm{SI}\right)$. AMS studies revealed that the Middle Triassic samples are characterized by inverse magnetic fabric and prolate AMS ellipsoids, whereas the Early Triassic specimens represent normal sedimentary fabric and oblate AMS ellipsoids. Inverse magnetic fabric can be carried by many minerals including: tourmaline, cordierite or goethite (Chadima et al., 2006). For investigated samples two models proposed by Rochette (1988) are highly probable: (1) presence of single-domain elongated magnetite grains or (2) presence of ferroan carbonates whose maximum susceptibility is parallel to the c-axis. Paleomagnetic results of the Botneheia Formation revealed only one characteristic NRM component characterized by steep inclination and maximal unblocking temperatures in range of $425-450^{\circ} \mathrm{C}$. In turn, the Early Triassic rocks record several NRM components with partially overlapping unblocking temperatures. We have concluded that different magnetic properties observed in studied rocks might be related to various lithologies but also to distinct tectonic and thermal histories associated with complex tectonic evolution of the Barents Sea Shelf.

\section{REFERENCES}

Chadima M., Pruner P., Šlechta S., Grygar T. \& Hirt A.M., 2006. Magnetic fabric variations in Mesozoic black shales, Northern Siberia, Russia: Possible paleomagnetic implications. Tectonophysics, 418, 145-162.

Rochette P., 1988. Inverse magnetic fabric in carbonate-bearing rocks. Earth and Planetary Science Letters, 90, 229-237. 